\title{
DETERMINATION OF THE EFFECTS OF COOLING RATE FROM SOLUTION TREATMENT ON THE MICROSTRUCTURE AND MECHANICAL PROPERTIES OF A PRECIPITATION STRENGTHENED, LOW THERMAL EXPANSTON ALLOY
}

\author{
E. A. Wanner, D. A. DeAntonio, R. K. Mahidhara \\ Carpenter Technology Corp. \\ P.0. Box 14662 \\ Reading, PA 19612-4662
}

\begin{abstract}
Segments of hot rolled Pyromet Alloy CTX-3 bar were solution treated at $1800^{\circ} \mathrm{F}$ and cooled to room temperature in various media, resulting in calculated cooling rates (from $1800^{\circ} \mathrm{F}$ to $1000^{\circ} \mathrm{F}$ ) ranging from $0.1^{\circ} \mathrm{F} / \mathrm{sec}$. to $\sim 66^{\circ} \mathrm{F} / \mathrm{sec}$. After subsequent overaging at $1425^{\circ} \mathrm{F} / 1150^{\circ} \mathrm{F}$, it was determined that both very slow and very rapid cooling after solution treatment resulted in extensive precipitation of the stable $\eta$ phase and a decrease in $\gamma^{\prime}$ content. Since $n$ contributes little to the strengthening of Alloy CTX-3, decreases in tensile and/or yield strength were associated with copious $n$ precipitation. However, improvements in $1000^{\circ} \mathrm{F}$ notch strcss rupturc life were associated with abundant grain boundary $\eta$ precipitation. SEM fractography of notch rupture specimens revealed increasing evidence of cleavage in specimens containing higher volume fractions of $\eta$ phase, suggesting that $n$ may reduce grain boundary sliding. It was also noted that after long term ( $>5000 h)$ exposure to rupture test conditions, dissolution of coarse $\gamma^{\prime}$ and precipitation of a fine $(<5 \mathrm{~nm})$, embryonic precipitate occurred. Results of this investigation indicate that incremental gains in notch rupture life are possible through control of the cooling rate after solution treatment in applications where slight decreases in tensile strength are tolerable.
\end{abstract}

Superalloys 1988

Edited by S. Reichman, D.N. Duhl, G. Maurer, S. Antolovich and C. Lund

The Metallurgical Society, 1988 
Pyromet ${ }^{\circledR}$ Alloy CTX-3 is a low thermal expansion superalloy based on a $\mathrm{Ni}-\mathrm{Fe}-\mathrm{Co}$ matrix of controlled composition. Titanium and columbium are present to promote formation of the metastable garnma prime $\left(\gamma^{\prime}\right)$ phase (fcc $\mathrm{Ni}_{3}(\mathrm{~T}, \mathrm{Al})$ ) in the austenitic matrix upon aging. To provide a preferred balance of tensile strength and ductility together with freedom from stress rupture notch sensitivity, extended aging treatments are typically spccified for this alloy. Such "overaging" treatments result in the precipitation of both cuboidal $\gamma^{\prime}$ particles and the stable, plate-1ike eta $(\eta)$ phase (hcp $\left.\mathrm{Ni}_{3}(\mathrm{Ti}, \mathrm{Cb})\right)$.

In the overaged condition, Pyromet Alloy CTX-3 typically exhibits 6 coefficients of thermal expansion $\left(\alpha^{\prime} \mathrm{s}\right)$ of approximately $4.0-4.5 \times 10^{-6} \mathrm{~F}^{-1}$ to $780^{\circ} \mathrm{F}$, values approximately $40-50 \%$ lower than exhibited by A1loy 718 , an austenitic Ni-Fe-base alloy. Between 750 and $850^{\circ} \mathrm{F}$, the austenitic Ni-Fe-Co matrix of Pyromet Alloy CTX-3 undergoes a ferromagnetic-to-paramagnetic transformation. The resultant decrease in magnetostriction causes mean $\alpha$ values from the inflection temperature upward to approach those of other austenitic superalloys. However, due to the substantially lower $\alpha$ in the ferromagnetic range, mean $\alpha$ values from room temperature to $1200^{\circ} \mathrm{F}^{\prime}$ remain approximately $30 \%$ lower than Alloy 718.

The typical microstructure of Alloy CTX-3 after solution treatment at $1800^{\circ} \mathrm{F}$ and overaging, as examined optically, contains palches of Widmanstatten nphase platelets in a partially recrystallized, austenitic matrix. Occasional regions of cellular $n$ precipitation are sometimes observed along grain boundaries. In addition, coarse $\gamma^{\prime}$ is occasionally visible at the inner regions of grains.

In a previous, unpub1ished investigation(1), $1.45^{\prime \prime} \times 1.38^{\prime \prime}$ cross section Pyromet Alloy CTX-3 bars which were solution treated, water quenched, then aged exhibited significantly lower room temperature and $1000^{\circ} \mathrm{F}$ tensile and yield strength levels than identically processed bars which were solution treated, air cooled, then aged. Optically, it was observed that the water quenched specimens contained a significantly higher volume fraction of $n$ phase than the air cooled specimens. In addition, it was observed that the $\eta$ platelets were substantially larger in the water quenched bars, frequently traversing entire grains. Examination by transmission electron microscopy (TEM) utilizing chromium shadowed parlodion structural replicas revealed large $\gamma^{\prime}$ denuded zones to be associated with the larger nplatelels in the waler quenched specimens. Additionally, an overall $\gamma^{\prime}$ deficiency was observed in the water quenched specimens. Based on these results, the present study was undertaken to attempt to quantify the relationship between cooling rate following solution treatment and the mechanical properties of Pyromet Alloy CTX-3. In addition, it was desired to determine the microstructural effects of post-solution cooling rate on the precipitation reactions accompanying overaging.

\section{Procedure}

Hot-rolled Pyromet Alloy CTX-3 bar stock (nominal composition, Table I), 1.45" x 1.38" in cross section was obtained from a production quantity. It was desired to vary cooling rate after solution treatment from a very slow cool (furnace cool @ $250^{\circ} \mathrm{F} / \mathrm{h}$ ) to a rapid quench (water quench of a $0.625^{\prime \prime} \mathrm{sq}$. bar). In addition, it was desired to investigate intermediate cooling rates simulating typical bar or rolled ring cross sections. Using a modification of Newton's law of heating and cooling(2), cooling rates were

$\overline{(B)-\text { registered }}$ trademark of Carpenter Technology Corporation 


\section{Table 1: Nominal Composition of Pyromet CTX-3 Alloy}

$\begin{array}{cc}\text { Element } & \text { Weight Percent } \\ \mathrm{C} & 0.015 \\ \mathrm{Si} & 0.15 \\ \mathrm{Cr} & 0.2 \\ \mathrm{Ni} & 38.25 \\ \mathrm{Cb} & 4.85 \\ \mathrm{Ti} & 1.6 \\ \mathrm{Al} & 0.1 \\ \mathrm{~B} & 0.007 \\ \mathrm{Co} & 13.6 \\ \mathrm{Fe} & \text { Balance }\end{array}$

approximated for various section sizes and quenching media.

Several bar segments were cut

longitudina11y to $0.625 " \mathrm{sq}$., while the remaining segments were milled and ground to $1.25^{\prime \prime} \mathrm{sq}$. Specially fabricated fixtures were used to contain the $1.25^{\prime \prime} \mathrm{sq}$. ground bars during solution treatment and cooling, thereby simulating larger ( 2 " $\mathrm{sq}$. or $3^{\prime \prime} \mathrm{sq}$ ) ) section sizes. The various cooling media used for the cooling simulations are shown in Table II, and for each simulation, the calculated cooling rate is shown in Table III, together with its equivalent in air cooled or water quenched bar/billet size.
Table II: Cooling* Media Used for Pyromet CTX-3 Specimens

\begin{tabular}{|c|c|}
\hline $\begin{array}{l}\text { Specimen } \\
\text { Identity } \\
\text { FC5 } \\
\text { VL3 } \\
\text { VL2 } \\
\text { AC1 } \\
\text { AC5 } \\
\text { OQ3 } \\
\text { OQ2 } \\
\text { WO3 } \\
\text { OQ1 } \\
\text { OQ5 } \\
\text { WO1 } \\
\text { WO5 }\end{array}$ & 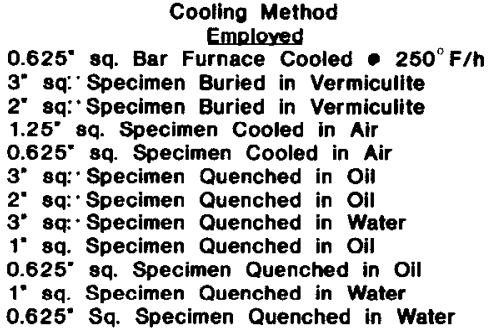 \\
\hline
\end{tabular}

Table III: Calculated Quench Rates* from Solution Temperature $\left(1800^{\circ} \mathrm{F}\right)$ for Pyromet CTX-3 Specimens

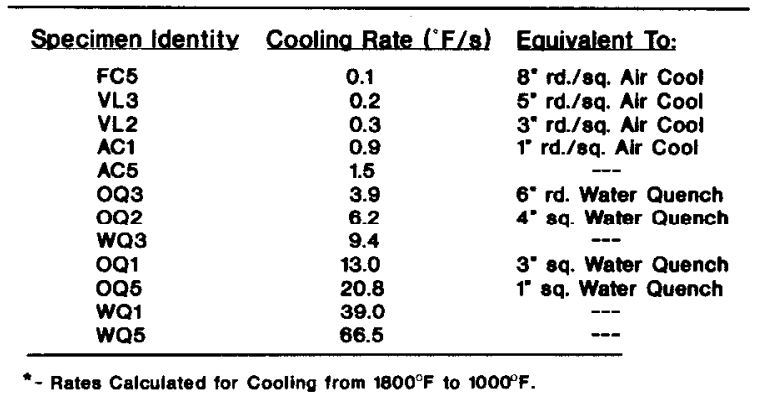

After solution treatment at $1800^{\circ} \mathrm{F}$ for 1 hour and cooling to room temperature at the desired rate, specimens for residual stress measurement (via x-ray diffraction) were removed from each of the $1.25^{\prime \prime} \mathrm{sq}$. bar segments. All bar segments were then overaged using a treatment of $1425^{\circ} \mathrm{F} / 12 \mathrm{~h} /$ furnace cool at $100^{\circ} \mathrm{F} / \mathrm{h}$ to $1150^{\circ} \mathrm{F} / \mathrm{hold} 8 \mathrm{~h} /$ air cool. After overaging, the $1.25^{\prime \prime} \mathrm{sq}$. bar segments were quartered longitudinally. Room temperature tensile specimens with 0.252 " gage diameters were single point machined from the overaged blanks. Notched stress rupture specimens, with $0.250^{\prime \prime}$ notch diameters, $0.354 "$ shoulder diameters, and $0.0363^{\prime \prime}$ root radii with a $60^{\circ}$ included notch angle $\left(\mathrm{K}_{t}=\sim 2.0\right)$ were also prepared from the overaged specimen blanks. Low stress cylindrical grinding was used to manufacture these specimens, since previous testing (3) had shown that single point turning produced specimens with inconsistent rupture lives. This effect was presumably due to non-uniform levels of residual stress in the notch.

Hardness measurements (BHN) were taken using samples representing each of the 1.25" sq. bars, as well as sample FC5 after solution treatment. Notch stress rupture testing was conducted at $1000^{\circ} \mathrm{F}$ with a constant load applied to generate an initial stress level of $120 \mathrm{ksi}$. Tests were continued to failure or to a maximum of $5000 \mathrm{~h}$ with no overloading. Tensile tcsts wcrc conducted at room temperature at a free-running crosshcad spccd of $0.0625 \mathrm{in} / \mathrm{min}$.

Longitudinal specimens for metallographic examination were removed from each fully heat treated bar prior to machining. In addition, thin foil specimens for TEM examination were prepared from material representative of 
each cooling rate. Foils were also prepared from selected broken mechanical test specimens. Chromium shadowed parlodion structural replicas were prepared to examine the $\gamma^{\prime}$ and $n$ phase distribution over larger areas of the specimens.

\section{Results and Discussion}

\section{Hardness Testing}

Hardness test data for the solution treated specimens are presented in Table IV. These data show that the slowly cooled specimens (those cooled at rates less than $\chi^{\circ} \mathrm{F} / \mathrm{sec}$.) possess significantly higher hardness than specimens cooled more rapidly. Based on computations performed using the calculated cooling rates of Table II for specimens VL-2, VL-3, and FC-5; the three specimens exhibiting higher solution treated hardness; a minimum of 20 minutes and a maximum of 1.3 hours elapsed during which these samples were within the favorable $\gamma^{\prime} / n$ precipitation temperature range as predicted by Muzyka, et.al,(4) for a similar alloy. Thus, it is likely that some precipitation of $\gamma^{\prime}$ and possibly $\eta$ phase took place during the cooling of these specimens. The balance of the more rapidly cooled material passed through the favorable precipitation range in less than 6 minutes, an insufficient time period to allow for any substantial $\gamma^{\prime}$ or $\pi$ precipitation.

Examination of selected transverse bar specimens using light optical microscopy showed no visible evidence of precipitation during cooling in specimens VL2 and VL3. However, it is possible that fine $\gamma^{\prime}$ or $\eta$ phase, not resolvable using light microscopy, was responsible for the observed hardness increase.

Table IV: Hardness Results for Solution Treated Specimens Cooled at Various Rates

$\begin{array}{cc}\text { Seecimen ldentity } & \text { Hardnese (BHN) } \\ \text { FC5 } & 358 \\ \text { VL3 } & 363 \\ \text { VL2 } & 363 \\ \text { AC1 } & 187 \\ \text { OQ3 } & 179 \\ \text { OQ2 } & 179 \\ \text { WO3 } & 174 \\ \text { OQ1 } & 170 \\ \text { WO1 } & 174\end{array}$

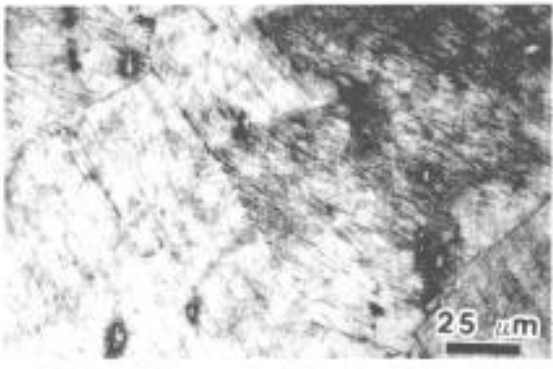

Fiqure 1. Optical Mierograph Showing Typical 7 Phase Destribution in Specimens VL2, AC1, and AC5 Elchant: Glyceregia
Table V: Room Temp. Tensile Properties of CTX-3 Cooled at Various Rates after Solution Treatment (Average of Duplicate Teata Reported)

\begin{tabular}{|c|c|c|c|c|c|}
\hline $\begin{array}{l}\text { Specimen } \\
\text { identity }\end{array}$ & $\begin{array}{c}\text { Quench Rate } \\
\text { (F/oec) }\end{array}$ & $\begin{array}{l}0.27 \text { Y.S. } \\
\text { (ksil) }\end{array}$ & 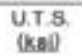 & $\begin{array}{c}\text { Elongation } \\
\text { (\$) }\end{array}$ & $\begin{array}{l}R . A \\
(\mathbf{N})\end{array}$ \\
\hline FC5 & 0.1 & 110.9 & 152.8 & 16.4 & 18.6 \\
\hline VL. 3 & 0.2 & 110.7 & 182.1 & 13.5 & 17.4 \\
\hline VL2 & 0.3 & 114.7 & 184.8 & 11.8 & 16.2 \\
\hline ACI & 0.0 & 115.2 & 164.7 & 14.0 & 16.7 \\
\hline ACS & 1.0 & 118.4 & 156.2 & 14.8 & 16.0 \\
\hline 003 & 3.9 & 111.9 & 156.6 & 11.8 & 16.0 \\
\hline 002 & 6. 2 & 109.8 & 158.6 & 13.0 & 17,3 \\
\hline wo3 & 9.4 & 113.2 & 161.0 & 132 & 17.0 \\
\hline 001 & 13.0 & 115.0 & 158.2 & 15.0 & 17.1 \\
\hline OQS & 20.8 & 108.2 & 152.8 & 16.6 & 20.3 \\
\hline WO1 & 38.0 & 108.5 & 151.4 & 15.8 & 18.2 \\
\hline Wดิ & 66.6 & 92.8 & 140.4 & 16.6 & 19.2 \\
\hline
\end{tabular}

$\underline{\text { Tensile Testing }}$

Results of room temperature tensile tests performed using overaged specimens representing each postsolution-treatment cooling rate are presented in Table $V$. These results indicate that an optimal combination of tensile and yield strengths in overaged A11oy CTX-3 are obtained when specimens are cooled at rates ranging from approximately 0.4 to $1.4^{\circ} \mathrm{F} / \mathrm{sec}$, as calculated using Newton's law of heating and cooling, from a solution treatment temperature of $1800^{\circ} \mathrm{F}$. 
Metallographic examination of specimens cooled within this range (specimens VL2, $\mathrm{AC1}$, and $\mathrm{AC5}$ ) revealed low to moderate $\eta$ platelet concentrations, with most1y sma11 platelet size (Figure 1). Lamellar grain boundary $n$ precipitation was evident in each of these specimens, however the most extensive lamellar precipitation was observed in specimen AC1.

At the slower cooling rates, a decrease in yield strength was noted, with specimen FC5 (cooled at $0.07^{\circ} \mathrm{F} / \mathrm{sec}$.) also displaying a decrease in tensile strength. Specimens FC5 and VL3 were observed to possess markedly different $\eta$ precipitation characteristics, as shown in Figure 2 . While both specimens contained relatively small $\eta$ platelets, a considerably higher volume fraction of $\eta$ was present in specimen FC5. As shown in the TEM micrograph of Figure 3, localized regions of heavy Widmanstatten $n$ platelet precipitation result in regions lean in $\gamma^{\prime}$, the primary strengthening precipitate in Alloy CTX-3. This is expected since both precipitating phases consume Ti. The effect of $n$ platelet precipitation in lieu of or upon dissolution of $\gamma^{\prime}$ particles is reflected in the lower tensile strength of FC5 as compared to specimen VL3. Since specimens FC5 and VL3 possessed similar yield strengths with specimen VL3 displaying a significantly higher tensile strength, it can be surmised that, while the dislocation initiation was similar in both samples, dislocation motion was impeded to a greater extent in specimen VL3, further supporting the belief that a higher volume fraction of $\gamma^{\prime}$ existed in specimen VL3. This effect was also noted in that tensile ductility was slightly lower in specimen VL3 than in FC5.
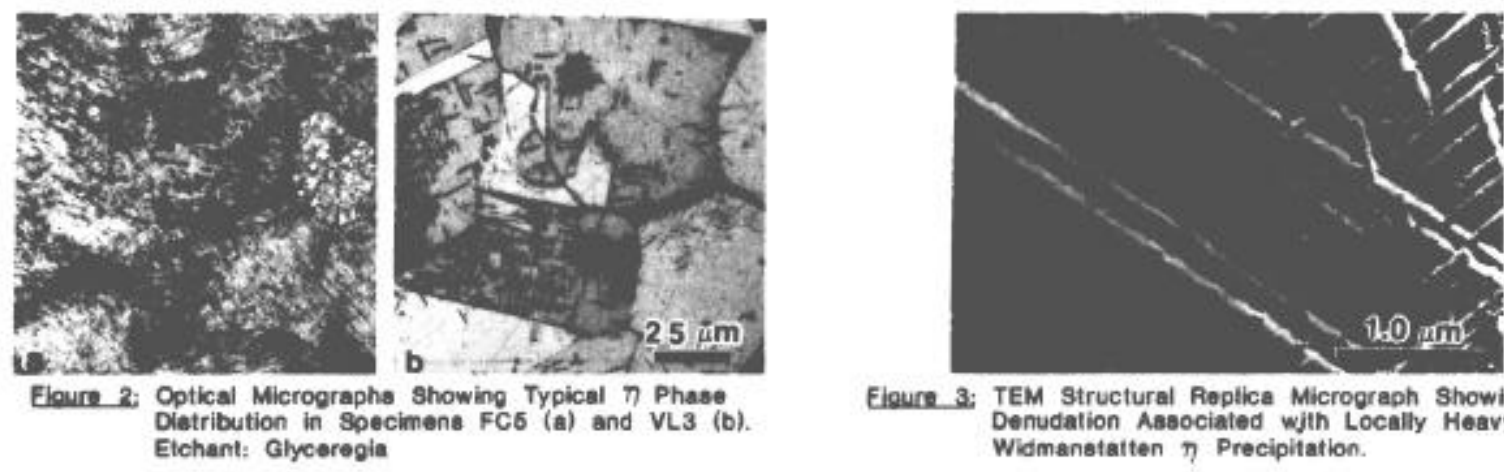

Eigure 3: TEM Structural Replica Micrograph Showing $\gamma^{\text {* }}$ Denudation Aasociated with Locally Heavy Widmanataiten $\eta$ Precipitation.

At cooling rates greater than $14^{\circ} \mathrm{F} / \mathrm{sec}$, tensile and yield strength levels were observed to decrease with increasing calculated cooling rate, with the exception of specimens $0 Q 1$ and WQ3. These specimens, cooled at 13.0 and $9.4^{\circ} \mathrm{F} / \mathrm{sec}$, respectively, possessed higher yield strengths than expected, as indicated by specimens cooled more slowly (0Q2) or more rapidly (0Q5). As can be seen in Figures 4 and 5, specimens OQ1 and WQ3 contained far fewer $n$ platelets than did specimens $0 Q 2$ and $0 Q 5$, leading to a potentially higher $\gamma^{\prime}$ volume fraction than anticipated.

Specimens $\mathrm{OQ3}, \mathrm{OQ2}, \mathrm{OQ5}$, WQ1, and WQ5; representing calculated cooling rates of $3.9,6.2,20.8,39.0$, and $66.5^{\circ} \mathrm{F} / \mathrm{sec}$, respectively; exhibited a clear trend of decreasing tensile and yield strength with increasing cooling rate. Metallographic examination of these specimens showed that both $\eta$ platelet volume fraction and $\eta$ platelet size increased with increasing cooling rate. This is especial1y evident when specimens OQ2, OQ5, WQ1, and WQ5 are compared (Figure 5). As stated previously, locally heavy $\eta$ precipitation resulted in $\gamma^{\prime}$-lean regions. In the specimens containing the elongated $\eta$ platelet morphology, $\gamma^{\prime}$ denuded zones associated with the platelets have been observed to overlap, leading to relatively large intragranular regions essentially devoid of $\gamma^{\prime}$ precipitation. It is suspected that such large $\gamma^{\prime}$-free zones were developed in specimens WQ1 and 

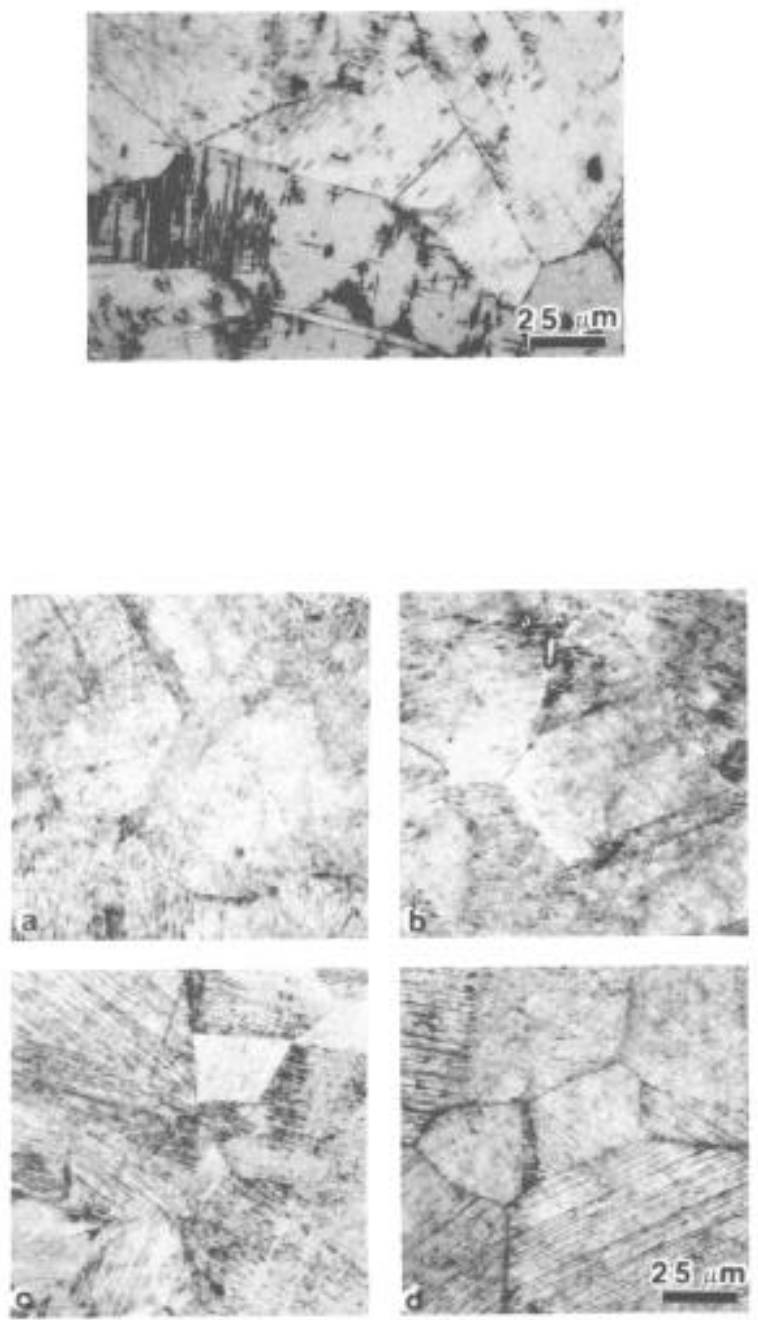

Figure 6. Optical Micrographs Showing Typical 7 Phase Diatribution in Specimena 002 (a), 006 (b), WO 1 (c), and WQ5 (d). Note increasing $\pi$ platelet length with increasing cooling rate. Etchant: Glyceregis
WQ5, leading to sizeable decreases in tensile and yield strengths. A transmission electron micrograph showing such zones is presented in Figure 6. SEM fractography was also conducted using room temperature tensile specimens from each of the three previously mentioned conditions. This examination showed no difference in fracture mode based upon the extent of precipitation, indicating that within the range of $\eta$ contents examined, $n$ phase has little or no strengthening effect at room temperature.

\section{Stress Rupture Testing}

Data presented in Table VI show that rupture life at $1000^{\circ} \mathrm{F} / 120 \mathrm{ksi}$ for specimens heat treated as $1.25^{\prime \prime} \mathrm{sq}$. bar was

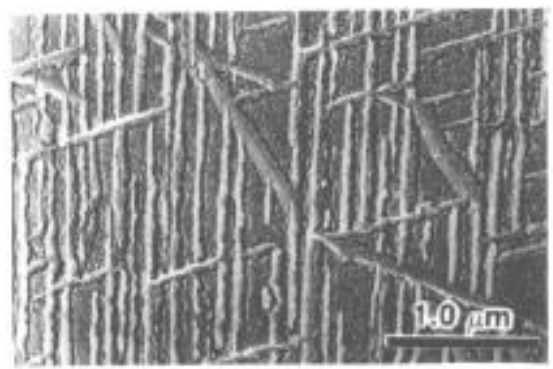

Fioure 6: Structural Replica Micrograph Showing Absence of $y^{*}$ in the Vicinity of Heavy $n$ Precipitation

inversely related to tensile strength at room temperature. As shown in Figure 7 , the exclusion of data generated using 0.625 " $\mathrm{sq}$. bar specimens results in a clear trend of decreasing notch rupture life with increasing room temperature tensile strength (to $\sim 160 \mathrm{ksi}$ ).

Table VI: Notch Stress Rupture Properties of CTX-3 Cooled at Various Rates after Solution Treatment (Average of Duplicate Tests Reported)

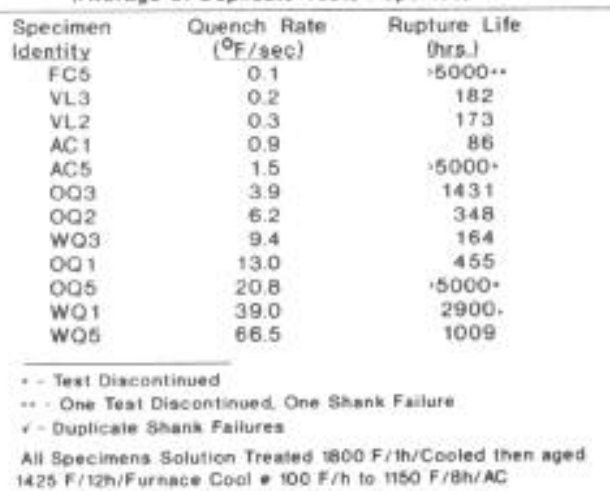

Figure 7: Notch Stress Rupture Life of CTX-3 Alloy Tested at $1000^{\circ} \mathrm{F} / 120 \mathrm{ksi}$ (Average of Duplicate Tests Reported)

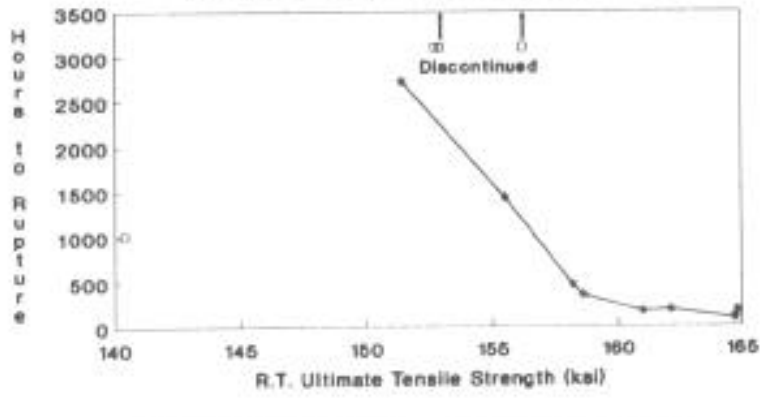

$\rightarrow-1.25^{\circ}$ sq. Specimens a $0.825^{\circ}$ se. Specimens

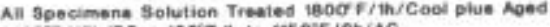
$14267 / 12 \mathrm{eh} / \mathrm{FC} \cdot 100^{\circ} \mathrm{F} / \mathrm{h}$ to $1150^{\circ} \mathrm{F} / 8 \mathrm{~h} / \mathrm{AC}$ 
The apparent correlation of increasing notch rupture life with decreasing tensile strength indicates a beneficial effect of $\eta$ phase for notch strengthening. SEM fractographic analyses of three selected specimens representing short (AC1), intermediate (WQ5) and 1ong (FC5) rupture lives, were conducted. It was observed in all conditions that fracture initiated in a region beneath the specimen surface, propagating toward the surface. In specimen $\mathrm{ACl}$, where a rupture life of $\sim 85 \mathrm{~h}$ was reported and minimal quantities of $n$ precipitation were observed, only intergranular fracture was noted in the fracture initiation region (Figure 8a). Failure in the initiation region occurred by a grain boundary shear mechanism with extensive evidence of grain boundary sliding. In specimens FC5 and WQ5, where significantly longer rupture lives ( $\sim 5000 \mathrm{~h}$ and $\sim 1000 \mathrm{~h}$, respectively) and higher volume fractions of $n$ phase were observed, fracture initiation was mixed mode, with evidence of cleavage facets in many grains (Figure 8b and c). In all specimens, transgranular (cleavage) fracture was observed in the fast-fracture regions.
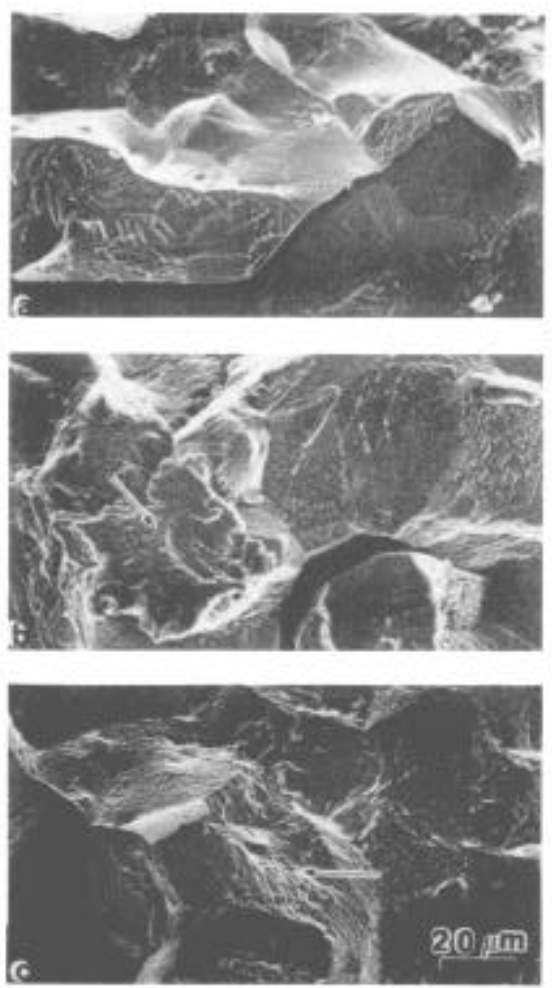

Esoure 8: SEM Fractographs of Notch Rupture Specimens AC1 (a), $80 \mathrm{~h}$ life: WOS (b), $1000 \mathrm{~h}$ lite: and FC6 (c), $8000 \mathrm{~h}$ lite. Note presence of clesvage facots (arrows) in (b) and (c)
The formation of cleavage facets in the fracture initiation regions of these specimens suggests that some grain boundary strengthening mechanism, absent in specimens $\mathrm{AC} 1$, was present in specimens WQ5 and FC5. TEM examination revealed substantially thicker $(>300 \mathrm{~nm})$ $\eta$ platelets on the grain boundaries of specimens FC5 and WQ5 (Figure 9a) than in the matrix. While grain boundary $\eta$ phase was also observed in specimen $\mathrm{ACl}$, its thickness was similar to that of the matrix $\Pi$ platelets $(\sim 100 \mathrm{~nm})$ (Figure 9b). The presence of fully developed 7 platelets on the grain boundaries of specimens FC5 and WQ5 suggests that this phase decreases stress rupture notch sensitivity by minimizing grain boundary sliding. The apparent propensity toward grain boundary sliding in specimen $\mathrm{ACl}$ may be due to insufficient grain boundary $\eta$ precipitation.

It is imperative when interpreting this notch stress rupture data that the effect of section size during heat

treatment be considered. In the case of the 0.625 " $\mathrm{sq}$. bars, which exhibited very long rupture lives, the center axis of the test specimen coincided with the centerline of the bar during heat treatment. In the case of the $1.25^{\prime \prime} \mathrm{sq}$. bars, the specimen axes were not coincident with the bar centerlines. Because of this, the severity of thermal gradients established and the state of residual thermal stress at the specimen axis were not consistent for the two bar sizes evaluated. Similar effects were averted in the simulated $2^{\prime \prime} \mathrm{sq}$. and $3^{\prime \prime} \mathrm{sq}$. bar specimens, since thermal stresses are unlikely to have been transmitted across the interface between the fixture blocks and the 1.25" sq. bar surface. Since residual stresses have been shown to promote formation of the more stable $\eta$ phase at the expense of the metastable ' $r$ ' precipitate $(5,6)$, and since increased $\eta$ precipitation has been correlated with increased rupture life, it is likely that the anomolous stress rupture results of specimens FC5, AC5, and $0 Q 5$ can be explained by section size thermal stress effects. The shorter rupture 

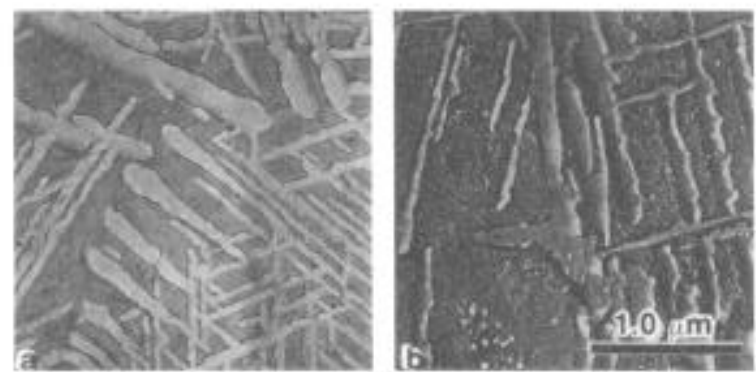

Figure 2. Structural Replica Micrographs Showing Thick Grain Boundary 7 . Platelets in Specimens AC? la and FC5 (b). Note substantially thicker platelets in $\mathrm{FC5}$ (b). life of specimen WQ5 may be explained by the fact that tensile strength was extremely low in this material. Since rupture testing was conducted at $1000^{\circ} \mathrm{F} / 120 \mathrm{ksi}$ and specimen WQ5 exhibited a room temperature UTS of on $1 \mathrm{y} \sim 140 \mathrm{ksi}$, it is 1 ikely that the intrinsic strength of this specimen was lower than necessary to provide a long rupture life.

Additional Evaluations

It has been established that the tensile and notch stress rupture properties of Pyromet Alloy CTX-3 are related to microstructural features which are affected by cooling rate from the solution treatment temperature. As yet, the mechanism by which cooling rate affects the precipitation reactions during subsequent overaging has not been determined. Differences in residual stresses in the specimens solution treated and cooled as

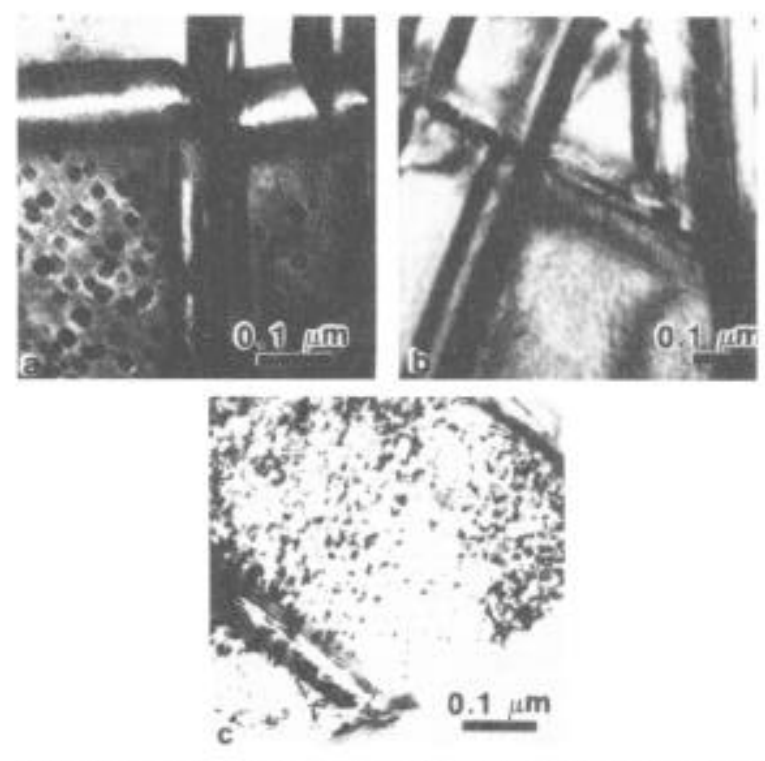

Eioure 1Q: TEM Thin Foil Micrographs from Fracture Region of Notch Rupture Specimens AC1 (a), WOS (b). FCE (c). Note coarse $y$ in (a), absence of $\gamma^{\prime}$ in (b), and fine precipitate in (c). $1.25^{\prime \prime} \mathrm{sq}$. bars were measured by determining shifts in the $2 \Theta$ angle for a (220) matrix reflection. No shifting of $2 \Theta$ angles was observed for any of the eight specimens examined, indicating that any differences in residual stress which may exist were undetectable.

Thin foil specimens from the notch areas of three selected notch stress rupture specimens were examined via TEM. Specimens ACl, WQ5, and FC5, exhibiting $\sim 80,1000$, and $5000 \mathrm{~h}$ rupture lives, respectively, were selected for this study.

Examination of the specimen microstructures in the vicinity of the stress rupture fractures revealed distinct differences. Specimen AC1, showing a rupture life of $\sim 80 \mathrm{~h}$, was found to contain primarily $\gamma^{\prime}$

strengthening precipitates interspersed with $n$ platelets (Figure 10a). Specimen WQ5, with a 1000 h rupture life, contained no detectable $Y^{\text {' }}$ precipitates (Figure $10 \mathrm{~b}$ ), with only 7 phase platelets observed. In specimen FC5, which exhibited a rupture life in excess of $5000 \mathrm{~h}$, copious precipitation of fine $(<5 \mathrm{~nm})$ particles was observed, with little or no coarse ( $\sim 40 \mathrm{~nm}) \gamma^{\prime}$ (Figure 10c). Examination of FC5 specimens not exposed to the rupture test conditions did not reveal the presence of fine $\gamma^{\prime}$; rather, only coarse, non-uniform $\gamma^{\prime}$ and $\eta$ phase were observed. This indicates that during rupture testing, coarse $\gamma^{\prime}$ particles were dissolved and replaced by much finer particles of another crystal structure. This is supported by the fact that no particle ripening was observed. Since the fine precipitate was observed in its embryonic stade (diameter $<5$ 
$\mathrm{nm}$ ), identification by electron diffraction analysis was not possible. It is also possible, due to the non-uniform precipitation pattern observed in these specimens, that the fine, embryonic particles observed were actually $\gamma^{\prime}$ particles precipitating in regions previously devoid of $\gamma^{\prime}$ precipita-

tion. In either case, the fine particle size and relatively dense distribution would increase the resistance to dislocation bypass, thereby

increasing rupture life at $1000^{\circ} \mathrm{F}$.

\section{Conclusions}

Pyromet A1loy CTX-3 bar specimens were solution treated $1800^{\circ} \mathrm{F} / 1 \mathrm{~h}$ and cooled to room temperature at calculated cooling rates ranging from 0.07 to $66.5^{\circ} \mathrm{F} / \mathrm{sec}$. (rates calculated for cooling from $1800^{\circ} \mathrm{F}$ to $1000^{\circ} \mathrm{F}$ ), followed by overaging $1425^{\circ} \mathrm{F} / 12 \mathrm{~h} /$ furnace cool @ $100^{\circ} \mathrm{F} / \mathrm{h}$ to $1150^{\circ} \mathrm{F} / 8 \mathrm{~h} / \mathrm{air} \operatorname{coo} 1$. Evaluations of the resultant room temperature tensile properties, $1000^{\circ} \mathrm{F} / 120 \mathrm{ksi}$ notch stress rupture properties, and microstructures led to the following conclusions:

1. Higher levels of yield strength were obtained at cooling rates ranging from $0.3-1.5^{\circ} \mathrm{F} / \mathrm{sec}$. These rates yielded microstructures containing low to moderate volume fractions of $n$ platelets.

2. Both slower and more rapid cooling rates resulted in precipitation of larger quantities of $\eta$ phase, leading to significantly lower levels of tensile and yield strengths.

3. Specimens cooled at extremely rapid rates after solution treatment were found to precipitate highly elongated, closely spaced nplatelets, leading to pronounced decreases in tensile and yield strengths.

4. Notch stress rupture life at $1000^{\circ} \mathrm{F} / 120 \mathrm{ksi}$ was inversely related to tensile strength at room temperature.

5. Fractographic analysis showed that specimens exhibiting longer rupture lives contained mixed mode fracture in the initiation region, while those with shorter lives contained shear (intergranular) fracture only. In combination with the observations of optical and electron microscopy, this suggests a bencficial grain boundary strengthening effect of $\eta$ phase.

6. After long term stress rupture testing, dissolution of coarse $(240 \mathrm{~nm})$ $\gamma^{\prime}$ and formation of a fine $(<5 \mathrm{~nm})$ precipitate was observed.

7. A1though air cooling resulted in optimized yie1d strength, relative1y low notch rupture life was exhibited by the larger section (1.25" sq.) air cooled specimens. In applications where incremental gains in notch rupture life are required and slight decreases in yield strength are tolerable, cooling rates more rapid than air cooling may be worthy of investigation. 
(1) Wanner, E. A., "Investigation of Low Tensile Strength in Hot Rolled Pyromet CTX-3 Bars," (Carpenter Technology Corp., 1987).

(2) Schumann, Jr., R. Metallurgical Engineering, Vol. 1, Engineering Principles (Reading, MA: Addison-Wesley, 1952), 259-283.

(3) Wanner, E. A., Unpublished Research (Carpenter Technology Corp., 1985).

(4) Muzyka, D. R., C. R. Whitney, and D. K. Schlosser, "Physical Metallurgy of a New Controlled-Expansion Superalloy," Journal of Meta1s, $27(7)(1975) 11-15$.

(5) Mihalisin, J. R. and R. F. Decker, "Phase Transformations in Nicke1Rich, Nicke1-Titanium-Aluminum Alloys," Trans. AIME, 218 (1960) 507515 .

(6) Wallwork, G. and J. Cro11, "A Review of the Strengthening Mechanisms in Iron and Nickel Based Fe-Ni-Cr Alloys Used at High Temperatures," Reviews on High-Temperature Materials, 3(2)(1976) 106. 